\title{
Immunologic Factor Process
}

National Cancer Institute

\section{Source}

National Cancer Institute. Immunologic Factor Process. NCI Thesaurus. Code C40582.

Any process which promotes expression of immunologic factors, their secretion, binding to cognate receptors or intracellular signaling, and results in functional responses in the immune system. This process is involved in regulating immune cell populations and coordinating systemic responses. 